Pacific Northwest

National Laboratory

Operated by Battelle for the

U.S. Department of Energy

\section{Estimated Entrainment of Dungeness Crab During Maintenance Dredging of the Mouth of the Columbia River, Summer 2002}

\author{
W. H. Pearson \\ G. D. Williams \\ J. R. Skalski
}

March 2003

Prepared for the U.S. Department of Energy under Contract DE-AC06-76RL01830 


\title{
DISCLAIMER
}

This report was prepared as an account of work sponsored by an agency of the United States Government. Neither the United States Government nor any agency thereof, nor Battelle Memorial Institute, nor any of their employees, makes any warranty, express or implied, or assumes any legal liability or responsibility for the accuracy, completeness, or usefulness of any information, apparatus, product, or process disclosed, or represents that its use would not infringe privately owned rights. Reference herein to any specific commercial product, process, or service by trade name, trademark, manufacturer, or otherwise does not necessarily constitute or imply its endorsement, recommendation, or favoring by the United States Government or any agency thereof, or Battelle Memorial Institute. The views and opinions of authors expressed herein do not necessarily state or reflect those of the United States Government or any agency thereof.

\author{
PACIFIC NORTHWEST NATIONAL LABORATORY \\ operated by \\ BATTELLE \\ for the \\ UNITED STATES DEPARTMENT OF ENERGY \\ under Contract DE-AC06-76RL01830
}

Printed in the United States of America

Available to DOE and DOE contractors from the

Office of Scientific and Technical Information,

P.O. Box 62, Oak Ridge, TN 37831-0062;

ph: (865) 576-8401

fax: (865) 576-5728

email: reports@adonis.osti.gov

\author{
Available to the public from the National Technical Information Service, \\ U.S. Department of Commerce, 5285 Port Royal Rd., Springfield, VA 22161 \\ ph: (800) 553-6847 \\ fax: (703) 605-6900 \\ email: orders@ntis.fedworld.gov \\ online ordering: http://www.ntis.gov/ordering.htm
}

This document was printed on recycled paper.

$$
(1 / 03)
$$




\title{
Estimated Entrainment of \\ Dungeness Crab During Maintenance Dredging of the Mouth of the Columbia River, Summer 2002
}

\author{
W. H. Pearson \\ G. D. Williams \\ Marine Sciences Laboratory \\ Pacific Northwest National Laboratory \\ Sequim, Washington \\ J. R. Skalski \\ Columbia Basin Research \\ School of Aquatic and Fishery Sciences \\ University of Washington \\ Seattle, Washington
}

March 2003

Prepared for

Portland District

U.S. Army Corps of Engineers

Portland, Oregon

Pacific Northwest National Laboratory

Richland, Washington, 99352 


\section{EXECUTIVE SUMMARY}

Dredging of the Columbia River has raised concerns about effects from dredging on Dungeness crab in the Columbia River Estuary. The Portland District of the U.S. Army Corps of Engineers (Corps) engaged the Marine Sciences Laboratory (MSL) of the U.S. Department of Energy Pacific Northwest National Laboratory to review the state of knowledge and conduct studies concerning effects from entrainment during dredging on Dungeness crab.

This document reports results from field sampling in the mouth of the Columbia River (MCR) between River Mile (RM) -3 and RM+3 from July 8 to October 13, 2002. MSL researchers directly measured crab entrainment aboard the Corps' dredge, Essayons, when the dredge was engaged in maintenance and operational dredging of the MCR. During 2002, the Essayons dredged over 3 million cubic yards (cy) of material from the MCR; researchers were aboard the Essayons from July to October 2002, when approximately 2.7 million cy were dredged. The team sampled 214 of 489 loads dredged at the MCR to yield a total number of 643 basket samples. A modified Dredge Impact Model (DIM) used the summer 2002 MCR entrainment rates and the total volumes of materials dredged in 2002 to project crab entrainment (E), adult equivalent loss (AEL), and loss to the fishery (LF) associated with the 2002 maintenance and operations dredging. A second set of DIM projections also used the 5-year averages of the total dredged volumes from the MCR to refine annual entrainment rate estimates. This document also reports on the salinities measured in the samples of dredged material taken in the MCR. An analysis of the influence of salinity on crab-entrainment rates based on both the MCR and upriver 2002 sampling appears separately in Pearson et al. (2002), which includes results from entrainment measurements at locations upriver from the MCR.

Dungeness crabs were found in the entrainment samples at the MCR in a contagious distribution. The entrainment rate for all age classes over all sampling in the MCR was 0.0603 crab per cy (i.e., one crab per approximately 16.6 cy dredged). Age $2+$ crabs had the highest entrainment rate $(0.0322 \mathrm{crab}$ per cy) in the MCR, whereas the $0+$ crab had the lowest ( 0.0033 crab per cy). For the six different sampling periods within the MCR, the entrainment rates for the $1+$ crab decreased as those for the $2+$ and older $\mathrm{crab}$ increased. The regression of the entrainment rates for $1+$ crab against the entrainment rates of the $2+$ and older crab was inverse and significant $(\mathrm{p}=0.022)$ with an $\mathrm{R}^{2}$ of $77 \%$. The sex ratio of the older crab entrained in the MCR was significantly skewed to the females. For $1+, 2+$, and $3+\mathrm{crab}$, the percentages that were female were $61 \%, 82 \%$, and $83 \%$, respectively.

A modified DIM was used to calculate the E, AEL at age 2+ and age 3+, and the LF for dredged volumes sampled aboard the Essayons in the summer of 2002 (Appendix A). Coefficients of variation associated with all these terms were under $5 \%$, and age class $2+$ and $3+$ crab contributed over $95 \%$ of the AEL in the MCR. The DIM was also used to project the E, AEL at age 2+ and age 3+, and LF for total 2002 and annual 5-year average dredged volumes collected by both the Essayons and the contractor dredges, although associated variance and confidence limit calculations were limited to Essayons 2002 volumes.

For the summer 2002 MCR Essayons dredged volume (3,017,176 cy), the estimated AEL at age 2+ was 118,326 crabs with $95 \%$ confidence limits from 107,300 to 129,352 crabs. The estimated AEL at age $3+$ for summer 2002 was 53,247 crabs, with $95 \%$ confidence limits from 48,269 to 58,225 crabs. The projected LF for total summer 2002 MCR Essayons dredged volumes was 6,868 crabs with 95\% confidence limits from 6,256 to 7,480 crabs. Because female crabs appeared in the entrainment samples at a higher rate than did males, the AELs for females were higher than those for males. About $82 \%$ of the AEL at age 2+ in the MCR was comprised of female crab in 2002. 
For the summer 2002 MCR total dredged volume (4,600,378 cy) collected by both Corps and contractor dredges, the estimated AEL at age 2+ was 180,416 crabs, estimated AEL at age 3+ was 81,187 crabs, and projected LF was 10,471 crab (Table 5). For the 5-year average total MCR dredged volumes $(4,391,872$ cy), the estimated AEL at age 2+ was 172,238 crabs, estimated AEL at age 3+ was 77,507 crabs, and projected LF was 9,997 crabs (Table 5).

Salinity in dredged materials from the MCR was close to that of ocean water for most of the sampling from July to October 2002 . About $82 \%$ of the salinity measurements were above 32 practical salinity units (PSU), 98\% were above 28 PSU, and less than 1\% were below 16 PSU.

At the high salinities found in the MCR, entrainment rates did not vary significantly with salinity. All of the regressions of the natural logarithm of the entrainment rates for various combinations of age classes against two measures of salinity were not significant. These results support the concept discussed in Pearson et al. (2002) that where bottom salinities are high most of the time, factors other than salinity are influencing crab distribution and entrainment rates. The results reported here, coupled with those in Pearson et al. (2002), indicate that low salinity influences crab-entrainment rates. 


\section{ACKNOWLEDGEMENTS}

This study would not have been possible without the assistance of a number of individuals. First of all, we would like to gratefully acknowledge the contributions of Captain Nyberg, Captain Henry, and each crew member aboard the Corps Dredge Essayons. Their accommodating attitude, gracious hospitality, and innovative problem solving provided a safe, enjoyable working atmosphere that enabled us meet all of our project goals. We would also like to thank the Battelle field crew: Mike Anderson, Gary Dennis, Heida Diefenderfer, Nathan Evans, Nancy Kohn, Lohna O'Rourke, John Southard, and Jeff Ward, who were adaptable to an ever-changing dredge schedule and often worked under difficult field conditions. The quality of this data is a tribute to their hard work and dedication. We would also like to thank Corps engineer Tim Burge for assistance in conducting flow velocity measurements, as well as Corps engineers Jim Calnon, Rachel Gumpenberger, and Calvin Hsieh for sampling efforts during the June field trials. This work was supported by the USACE Portland District. Mr. Kim Larson was the Corps Technical Representative. Ms. Doris McKillip was the Corps Project Manager for the MCR Dredging Project. 


\section{ACRONYMS}

$\begin{array}{ll}\text { AEL } & \text { adult equivalent loss } \\ \text { CI } & \text { confidence interval } \\ \text { CV } & \text { coefficient of variation } \\ \text { cy } & \text { cubic yards (also noted as } \mathrm{Y}^{3} \text { in some equations) } \\ \text { DIM } & \text { Dredge Impact Model } \\ \text { E } & \text { entrainment } \\ \text { LF } & \text { loss to fishery } \\ \text { MCR } & \text { mouth of the Columbia River } \\ \text { MSL } & \text { Marine Sciences Laboratory } \\ \text { PSU } & \text { practical salinity units } \\ \text { PT } & \text { pumping time } \\ \text { RM } & \text { river mile } \\ \text { YOY } & \text { young of the year }\end{array}$




\section{CONTENTS}

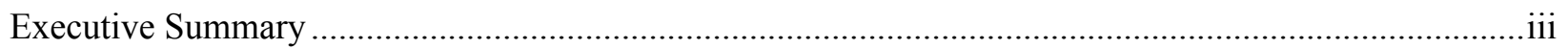

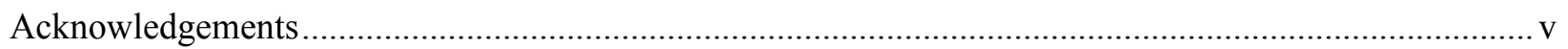

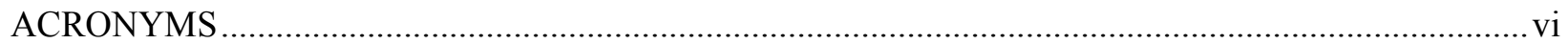

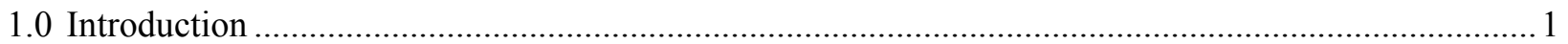

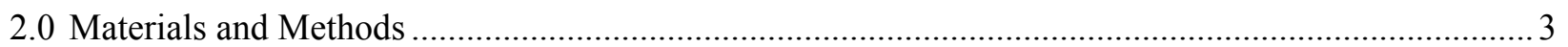

2.1 Methods for Direct Measurements of Entrainment Rates............................................................ 3



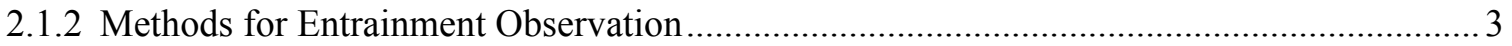

2.1.3 Modifications to Standard Sampling Procedures ............................................................... 4



2.1.5 Calculation of Adult Equivalent Loss and Loss to Fishery for Summer 2002 Dredged



2.1.6 Statistical Analyses and Calculation of Variance and Confidence Limits ............................ 6



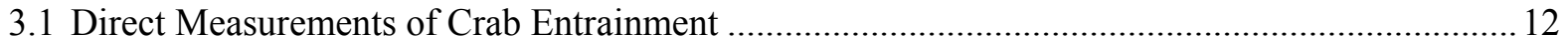

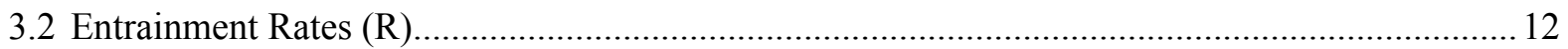

3.3 DIM Results for Dredged Volumes Accomplished in 2002 and for 5-year average Dredged



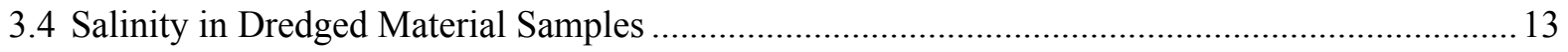

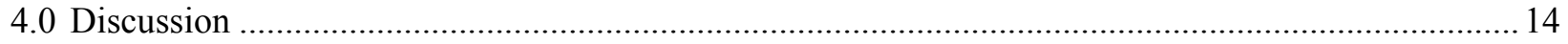

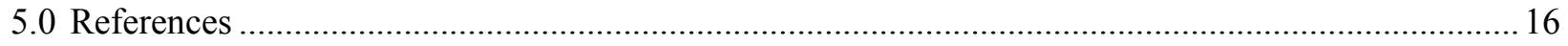

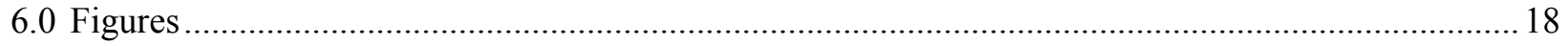

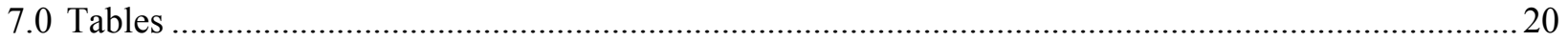

Appendix A - MCR Crab Entrainment Calculations, Summer 2002 Sampling Effort

Appendix B - Fish and Invertebrates Collected

Appendix C - MCR Crab Entrainment Projections, Summer 2002 and 5-Yr Average 


\section{FIGURES}

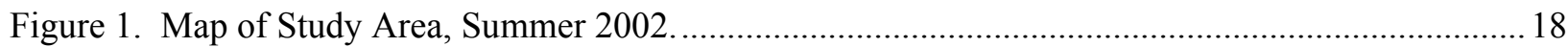

Figure 2. Diagram of the Piping and Valving on the Corps' Dredge Essayons, Summer 2002 ............... 19

Figure 3. Histogram of Salinity (PSU) in Dredged Material Samples from the MCR in Summer 2002... 19

\section{TABLES}

Table 1. Sampling Effort Associated with MCR Crab Entrainment Sampling on the Dredge Essayons

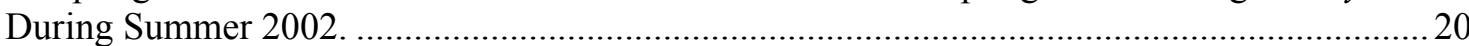

Table 2. Coefficients of Variation for Different Numbers of Basket Samples per Dredge Load. Based on

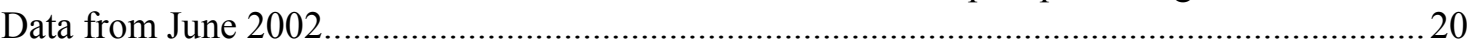

Table 3. Entrainment Rates by Crab Age Class from Direct Measurements in Summer 2002 ...............21

Table 4. Annual Dredged Volumes for the Mouth of the Columbia River, 1998-2002, Based on Federal Fiscal Years.

Table 5. Summary of Entrainment Rates (R), Entrainment (E), Adult Equivalent Loss (AEL), and Loss to Fishery (LF) for the Total Dredged Volumes Accomplished in the MCR During Summer 2002 and for the Five-Year Average; Essayons Summer 2002 Projections Include 95\% Confidence Intervals (CI).

Table 6. Contribution to Adult Equivalent Loss (AEL) by Male (M) and Female (F) Crab for 2002 Essayons Dredged Volumes.

Table 7. Results of Regression Analysis Between Natural Logarithm of the Entrainment Rates and Percentage of Salinity Observations Above 32 PSU and Below 16 PSU for the MCR, Summer 2002 


\subsection{INTRODUCTION}

Dredging of the Columbia River has raised concerns about associated effects on Dungeness crab in the Columbia River Estuary. The Portland District of the U.S. Army Corps of Engineers (Corps) engaged the Marine Sciences Laboratory (MSL) of the U.S. Department of Energy Pacific Northwest National Laboratory to review the state of knowledge and conduct studies concerning effects from entrainment during dredging on Dungeness crab. Previously, MSL performed crab studies for the Seattle District Corps Grays Harbor Navigation Improvement Project (e.g., Pearson 1987; Pearson and Woodruff 1987; Pearson et al. 1987). This document describes the field studies of crab entrainment during 2002 maintenance and operations dredging at the mouth of the Columbia River (MCR) from River Mile (RM) -3 to RM+3 (Figure 1). A separate report by Pearson et al. (2002) focuses on issues related to the proposed Columbia River Channel Improvement Project and presents results of field studies conducted from RM3 to RM24. Pearson et al. (2002) also presents a general background on Dungeness crab biology, the influence of salinity on crab distribution, and the use of a modified Dredge Impact Model (DIM) to estimate entrainment of Dungeness crab.

An understanding of how Dungeness crab use the estuary provides perspective on how that use may or may not expose them to dredging activity. Dungeness crab use both the nearshore ocean environment and the estuary in their life cycle (Armstrong et al. 1987; Rooper et al. 2002; Tasto 1983). In the Columbia River, Dungeness crab are found from the MCR to about RM17 (McCabe and McConnell 1989; McCabe et al. 1986), with different age classes using distinct parts of the estuary at different times of the year. In the spring, large numbers of young of the year (YOY) crab enter the estuaries of the West Coast as late megalopae and perhaps as first true crab. YOY (age 0+) crab in estuaries generally grow faster than those in the ocean (Armstrong et al. 1987). In spring and summer, 0+ crab can be found in the MCR, with annual average densities varying over two orders of magnitude from year to year (Larson 1993). Generally, age $0+$ crab are found in intertidal and shallow subtidal areas on substrates with shell hash, eelgrass, or other shelter (Armstrong et al. 1987). After growing to $20-\mathrm{mm}$ carapace width (CW), the $0+$ crab begin to move to subtidal areas. Age $1+$ and older crab use subtidal areas and forage over intertidal areas during high tide. Juvenile crab (age 1+) found in the estuary derive either from $0+$ crab that overwintered in the estuary or from 1+ crab entering the estuary in the summer. A recent survey of four West Coast estuaries by Rooper et al. (2002) indicates that Dungeness crab show consistent use of some estuarine habitat types. Side channel habitat near the estuary mouth has highest crab densities, with the lower estuarine main channel and upper estuary having significantly lower densities. The coastal estuaries are estimated to be the basis for $20 \%$ to $40 \%$ of West Coast Dungeness crab fishery production (D.A. Armstrong, personal communication). The estuaries appear to provide relatively steady contributions to annual crab production, whereas nearshore ocean environments provide crab production that is quite variable from year to year (D.A. Armstrong, personal communication).

Past studies have shown that Dungeness crab are entrained during dredging (Armstrong et al. 1987; Larson 1993; Wainwright et al. 1992). The age-class composition of entrained crab can vary by estuarine location and season. Mortality following entrainment and natural survival also varies by age class.

In the summer of 2002, MSL researchers directly measured crab entrainment aboard the Corps' dredge, Essayons, during maintenance and operational dredging of the Columbia River (Table 1, Figure 1). This document reports results from sampling in the MCR between RM-3 and RM+3. Pearson et al. (2002) reports the results from the sampling in locations upriver from the MCR (above RM+3). The Essayons is equipped with a special basket sampler, into which a portion of the dredged materials entering the vessel's hopper can be diverted. To support the calculations of the volume of dredged material sampled by the basket sampler, measurement of the fluid flow in the pipe leading to the basket sampler was conducted aboard the Essayons in September 2002 during dredging operations. Pearson et al. (2002) 
report the methods and results from the flow measurements, and the results of those flow measurements were used here in the calculation of entrainment rates. During 2002, the Essayons dredged over 3 million cubic yards (cy) of material from the MCR; researchers were aboard the Essayons from July to October 2002, when approximately 2.7 million cy were dredged. A modified DIM used the summer 2002 MCR entrainment rates and the volume of materials dredged in 2002 to project crab entrainment (E), adult equivalent loss (AEL), and loss to the fishery (LF) associated with the 2002 maintenance and operations dredging, as well as 5-year average annual dredged volumes. This document also reports on the salinities measured in the samples of dredged material taken in the MCR. An analysis of the influence of salinity on crab-entrainment rates based on both the MCR and upriver 2002 sampling appears separately in Pearson et al. (2002). 


\subsection{MATERIALS AND METHODS}

\subsection{Methods for Direct Measurements of Entrainment Rates}

\subsubsection{Statistical Design of Field Sampling}

Before the start of field measurements to determine entrainment rates for Dungeness crab on the Columbia River, the study team developed sampling designs and data analysis plans for the June sampling (Upriver) and for the July to October sampling (MCR and Upriver). To aid in the development of sampling design, the Portland District provided previously collected raw data on entrainment rates from the study of Larson (1993). Analysis of the Larson (1993) data revealed that the entrainment rates exhibited three major variance components: 1) day-to-day variability, 2) load-to-load variability, and 3) sample-to-sample variability within loads. The day-to-day variability was the dominant variance component. Pearson et al. (2002) describes how the statistical analysis was used to establish the design for upriver sampling in June 2002.

The sampling design for the summer 2002 (MCR and Upriver) was developed from the June 2002 (Upriver) sampling effort. Again, the day-to-day variability proved to be the dominant variance component. To select appropriate sampling rates to address load-to-load and sample-to-sample variances for the summer 2002 sampling, the study team statistician used the June 2002 data to calculate coefficients of variation (CV) for various combinations of sampling rates (Table 2). A CV of 0.125 was required to be $95 \%$ confident of having entrainment estimates within $\pm 25 \%$ of the true value. To obtain the desired precision for the summer 2002, the field team sampled each day of dredging, selecting half the loads at random and sampling three basket samples per load.

\subsubsection{Methods for Entrainment Observation}

Researchers conducted crab-entrainment studies aboard the Corps' dredge, Essayons, during six time periods from July through October 2002 when the dredge was engaged in maintenance and operations dredging of the MCR (Table 1, Figure 1). The data for estimation of crab-entrainment rates were derived from a two-stage sampling scheme. The first stage involved the random sampling of approximately half of the loads collected by the dredge. The second stage involved the random sampling of dredged material within the selected loads. Consequently, there were two aspects to the sampling protocol: 1) the random selection of loads, and 2) the random selection of "basket" samples within a load. In the MCR, three basket samples per load were processed. These basket samples were randomly distributed through the period of load collection, which typically took about an hour.

The four sets of data sheets used to record field data included load-by-load records, sample records, within-load records, and a daily log. The load-by-load record sheet included a randomly determined schedule constructed to indicate which loads to sample and which not to sample. Obtained from the Essayons' dredge logbook, total load volumes (cubic yards) and distances (feet) for all loads during the duration of the survey, whether sampled or not, were recorded on these load-by-load sheets. Data on individual basket samples taken within a load, including numbers, size, and sex of Dungeness crab entrained, were recorded on sample record sheets. Data on the number of crab, fish, and molluscs enumerated in each basket sample, along with the volume of the basket sample, were summarized on within-load record sheets. Finally, pertinent weather conditions, personnel involved, dredge operations, and deviations from normal operating procedures (e.g., repairs, gear modification), were noted in the daily $\log$. 
On-deck sampling proceeded as follows: when ready to sample, the researcher communicated to the vessel's bridge via radio to request the use of hydraulics to operate the crab basket sampler and gate valve, and for closure of starboard valve V17 (Figure 2). This configuration allowed the researcher to sample approximately half the volume of a single drag arm, or one quarter the total volume of material being loaded by the dredge. The researcher operated the hydraulic gate valve on deck to enable dredged material to flow into the basket sampler. The sampling time interval for the MCR was approximately $45 \mathrm{sec}$ and usually yielded a manageable volume of dredged material. Therefore, standard valve-timing procedures were as follows (time period in parentheses): the valve was opened (from 0 to $11 \mathrm{sec}$ ), valve remained fully open until the 30 second mark (from 11 to $30 \mathrm{sec}$ ), and valve was closed (from 30 to $43 \mathrm{sec}$ ). In all cases, the start time (hh:mm) and time increments (seconds) at which valve closure was initiated and fully closed were recorded. A later section here briefly explains the calculation of sample volumes; more detail on sample calculation appears in Pearson et al. (2002).

After stopping the flow of materials to the basket sampler, the researcher operated the second hydraulic valve to tilt the basket sampler on its side. The researcher communicated to the bridge that the hydraulic equipment was no longer required and received information on the average load rate and ship speed. The researchers measured and recorded the temperature (degrees Celsius) and salinity (practical salinity units) of pumped seawater obtained from a catch pan under the basket sampler system using a YSI Model 556 multiple probe system (MPS). Finally, the researchers emptied the basket sampler and used 5-gallon buckets to transfer the sample to the sorting table.

Researchers sorted whole and parts of living organisms from the sample and identified and enumerated individuals from the following taxa: crab (Cancer magister and other species), shrimp (e.g., Crangon spp.), razor clam, and all fish species. In cases in which an animal other than crab was crushed or pieces were collected, researchers counted the animal only if the head was present (see details below on quantifying crushed crab). Researchers noted the relative abundance of other species (e.g., olive snail, polychaetes) and recorded the species and total length (length from the tip of the upper jaw to the end of the caudal fin) of fishes.

The field team used calipers to measure the carapace width $(\mathrm{CW})$ of all crab and identified the sex of larger crab. If $1 / 2$ a carapace was present, researchers measured this portion and estimated total $\mathrm{CW}$. In cases in which a crab was crushed or pieces were collected, the field team consistently quantified only those crab for which the team collected more than $1 / 2$ carapace, or other matched pieces (e.g., telson, legs, chela, thorax) constituting $1 / 3$ of a crab. When these criteria were not met (e.g., only 2 legs collected), the researchers noted the presence of crab pieces qualitatively with a "YES" under the unidentified (UID) crab column on the record sheet. All crab and crab pieces were dumped into the dredge hopper to prevent duplicate counts on subsequent passes. Finally, the team recorded sediment type (e.g., sand, mud, gravel, shell) and vegetation, cleaned the basket sampler with a pressure washer, and restarted the sampling process. The field team completed all data sheets and corrected errors with a single line that was initialed and dated. At the end of each load, researchers reviewed the data sheets for completeness, accuracy, and legibility.

\subsubsection{Modifications to Standard Sampling Procedures}

The field team made slight changes to sampling procedures on some dates to maximize data collection during limited sampling windows or to compensate for mechanical delays. When a mechanical issue prevented sampling of a load, researchers skipped ahead on the random number schedule to the next load to be sampled when operations returned to normal.

There were also situations when because of extreme ebb tide currents or equipment damage, only a single drag arm was used to dredge the channel. In these cases, the volume of dredged material flowing into the 
vessel was reduced by half. To maintain adequate sample volumes flowing to the basket sampler, the port-side valves (V16 and V17) that distributed loads into the hold were closed when sampling occurred (Figure 2).

\subsubsection{Calculating Sample Volume}

In previous studies, the sample volumes used to estimate crab entrainments were based on full flows of a 66-cm discharge pipe over a 30- to 60-sec sampling interval (Larson 1993). Coarse estimates of mean flow rates of the discharge pipes were calculated on a load-by-load basis by dividing total pumping time (PT) by total load volume (cy) (see formulae on p. 7, Larson 1993). Therefore, sample volume was based on flow rate multiplied by sampling interval (total time valve was open).

Observations made during our June sampling effort (Pearson et al. 2002) suggested that procedures for calculating the sample volumes needed to be refined to take into account the depth of fluid in the pipe and the timing of opening and closing the hydraulic gate valves. For example, assuming the pipe is half full and standard valve-timing procedures (opening from 0 to $11 \mathrm{sec}$, fully open from 11 to $30 \mathrm{sec}$, closing from 30 to $43 \mathrm{sec}$ ), the effective sampling time is 36.4 seconds. Additional details on the calculation of effective sampling time are provided in Pearson et al. 2002.

Sample volume was calculated by multiplying effective sampling time (t) by mean load rate (cy/t) of the discharge pipe feeding the basket sampler. As in Larson (1993), mean load rates of the discharge pipe were calculated on a load-by-load basis by dividing total PT by total load volume in cy.

Flow measurements were conducted to clarify what proportion of the total flow (load rate) was diverted into the crab sampler and are described in Pearson et al. (2002). The resulting data indicate that flow coming into the crab basket sampler as a proportion of total flow coming onboard was 0.26 with a $95 \%$ confidence interval (CI) from 0.23 to 0.29 . These results provided no evidence to reject the value of 0.25 used by Larson (1993). Therefore, all calculations of sediment load and crab-entrainment rate use a factor of 0.25 to correct for the proportion of total flow (load rate) diverted into the basket sampler.

\subsubsection{Calculation of Adult Equivalent Loss and Loss to Fishery for Summer 2002 Dredged Volumes and Projected Volumes}

Armstrong and his colleagues (Armstrong et al. 1987; Wainwright et al. 1990; Wainwright et al. 1992) developed the DIM for use in the Grays Harbor Navigation Improvement Project of the Corps Seattle District. The model evolved over the years, and Wainwright et al. (1992) gives a succinct overview of its present form. In reviewing the model for use in gaining perspective on crab impacts in the Columbia River, Pearson et al. (2002) found the model structure to be generally applicable, but the entrainment function and the available data on crab density were not appropriate for estimating the effects of dredging on the Columbia River crab population and crab fishery. The entrainment function is probably sitespecific. More details of this analysis appear in Pearson et al. (2002).

To calculate E, AEL, and LF for summer 2002 and projected dredged volumes, the study team followed Pearson et al. (2002) in using a modified DIM. The modification does not depend on the entrainment function from Grays Harbor or previous trawl data from the Columbia River but instead employs the entrainment rates directly measured on the Corps' dredge Essayons in the Columbia River. The approach included the following steps:

1. Use entrainment rates ( $\mathrm{R}$ as crab per cy) directly measured on the dredge (no need to reference trawl density). 
2. Multiply these entrainment rates by the dredged volumes (cy) to give the number of crab entrained ( $\mathrm{E}$ as number of crab).

3. Apply the post-entrainment mortality rates from Wainwright et al. (1992) to give immediate losses.

4. Apply the natural survival rates from Wainwright et al. (1992) to give AEL (as number of crab) to midwinter age $2+$. (To obtain the AEL at age $2+$ for age $3+$ crab, the number of age $3+$ crab was back-calculated to its equivalent at age $2+$ using the reciprocal of the survival rate.)

5. Apply a survival rate of $45 \%$ from midwinter age $2+$ to midwinter age $3+$ (Armstrong et al. 1987) to give AEL at age $3+$.

6. Apply observed sex ratios and a harvest rate of 70\% (Wainwright et al. 1992) to give LF (as number of crab).

7. Calculate variance and $95 \% \mathrm{CI}$ for $\mathrm{E}, \mathrm{AEL}$, and LF.

8. Compare the LF with the landings (Washington Department of Fish and Wildlife and Oregon Department of Fish and Wildlife) from the Columbia River area to give perspective on the estimated impact.

In the DIM calculations, we projected E, AEL, and LF for the MCR for the volumes dredged in 2002 and for the 5-year averages of the dredged volume. Both the Corps' dredge, Essayons, and a private contractor dredge conducted the maintenance and operations dredging in the MCR; we assumed the same entrainment rates for both dredges.

Associated variance and confidence limits were calculated for MCR dredging conducted by the Corps' dredge Essayons in 2002 (see section 2.1.6). However, because we have no empirical data on entrainment rates for private contractor dredge efforts or for other years, associated projections assume:

- Entrainment rates are the same across vessels

- Entrainment rates are the same across years (i.e., no changes in annual abundance)

- Dredging effort sampled the same distribution of entrainment rates (i.e., sampled similarly the distribution of abundances)

Because of these assumptions, our projections are presented without additional measures of statistical precision.

\subsubsection{Statistical Analyses and Calculation of Variance and Confidence Limits}

\section{Estimating Numbers of Entrained Crab}

In a random sample of loads, crab-entrainment densities were estimated from a random sample of dredged material. Hence, the sampling design consists of a two-stage sampling scheme: Stage 1-Random sample of $h$ of $H$ loads, and Stage 2-Random sample of dredged material based $b$ of $B$ basket samples. The estimator of total entrainment for a specific age class (i.e., size class) of crab can be expressed as follows:

$$
\hat{E}_{i}=\frac{\sum_{j=1}^{h}\left[\frac{V_{j}}{b_{j}} \sum_{l=1}^{b_{j}} x_{i j l}\right]}{\sum_{j=1}^{h} V_{j}} \cdot \sum_{j=1}^{H} V_{j}
$$

where 
$x_{i j l}=$ number of age class $i(i=1, \ldots, A)$ crab/cy measured in the $l$ th basket sample $\left(l=1, \ldots, b_{j}\right)$ in the $j$ th load $(j=1, \ldots, h)$

$b_{j}=$ number of basket samples observed in the $j$ th load $(j=1, \ldots, h)$

$h=$ number of loads selected for sampling of crab density

$H=$ total number of loads at a dredged location

$V_{j}=$ total volume of dredged materials in the $j$ th load $(j=1, \ldots, h)$.

In turn, $x_{i j l}$ can be expressed in terms of the number of crab counted and the volume of the $l$ th basket sample of the $j$ th load where

$$
x_{i j l}=\frac{c_{i j l}}{w_{j l}}
$$

where

$$
\begin{aligned}
c_{i j l}= & \text { number of age class } i \text { crab }(i=1, \ldots, A) \text { in the } l \text { th basket sample }\left(l=1, \ldots, b_{i}\right) \text { in the } j \text { th } \\
& \text { load }(j=1, \ldots, h) \\
w_{j l}= & \text { volume of the material sampled in the } l \text { th basket sample }\left(l=1, \ldots, b_{i}\right) \text { in the } j \text { th load } \\
& (j=1, \ldots, h) .
\end{aligned}
$$

As such, the estimator of total crab entrainment for age class $i$ crab $(i=1, \ldots, A)$ can be expressed as

$$
\hat{E}_{i}=\frac{\sum_{j=1}^{h}\left[V_{j} \frac{\sum_{l=1}^{b_{j}} c_{i j l}}{\sum_{l=1}^{b_{j}} w_{j l}}\right]}{\sum_{j=1}^{h} V_{j}} \cdot \sum_{j=1}^{H} V_{j} .
$$

Estimators (1) and (2) will be the same if sample values $w_{i j}=w_{i}$ are equal within a load. Because sample volumes varied between basket samples, estimator (2) is the preferred estimator of total entrainment.

The variance of $\hat{E}_{i}$ is found by taking the variance in stages. The variance of $\hat{E}_{i}$ (Equation 2) can then be expressed as follows:

$$
\operatorname{Var}\left(\hat{E}_{i} \mid E_{i}\right)=H^{2}\left(1-\frac{h}{H}\right) \frac{\sum_{j=1}^{H}\left(V_{j} R_{i j}-R_{i} V_{j}\right)^{2}}{h(H-1)}+\frac{H}{h} \sum_{j=1}^{H}\left[V_{j}^{2} \cdot \operatorname{Var}\left(\hat{R}_{i j}\right)\right]
$$

where 


$$
\begin{gathered}
\left.R_{i j}=\frac{\sum_{l=1}^{B_{j}} c_{i j l}}{\sum_{l=1}^{B_{j}} w_{j l}}=\text { true density of age class } i \text { crabs (i.e., crabs } / Y^{3}\right) \text { in the } j \text { th load }(j=1, \ldots, H) ; \\
\left.R_{i}=\frac{\sum_{j=1}^{H} R_{i j} V_{j}}{\sum_{j=1}^{H} V_{j}}=\text { true density of crabs (i.e., crabs } / Y^{3}\right) \text { across all } H \text { levels; } \\
\operatorname{Var}\left(\hat{R}_{i j}\right)=\frac{\left(1-\frac{b_{j}}{B_{j}}\right)}{b_{j} \bar{w}_{j}} \frac{\sum_{l=1}^{B_{j}}\left(c_{i j l}-R_{i j} w_{j l}\right)^{2}}{\left(B_{j}-1\right)}
\end{gathered}
$$

and where

$$
\begin{aligned}
& \bar{w}_{j}=\frac{\sum_{l=1}^{B_{j}} w_{j l}}{B_{j}}=\text { average volume of basket sample in the } i \text { th load; } \\
& B_{j}=\text { total number of possible basket samples within the } j \text { th load. }
\end{aligned}
$$

Variance formula (3) cannot be used to analyze the field data because it is dependent upon unknown parameter values. Instead, an estimated variance must be calculated and used in confidence interval estimates.

An approximately unbiased variance estimator for $\hat{E}$ can be written as follows:

$$
\widehat{\operatorname{Var}}\left(\hat{E}_{i} \mid E_{i}\right)=H^{2}\left(1-\frac{h}{H}\right) \frac{\sum_{j=1}^{h}\left(V_{j} \hat{R}_{i j}-\hat{R}_{i} V_{j}\right)^{2}}{(h-1)}+\frac{H}{h} \sum_{j=1}^{h} V_{j}^{2} \cdot \widehat{\operatorname{Var}}\left(\hat{R}_{i j}\right)
$$

where

$$
\hat{R}_{i j}=\frac{\sum_{l=1}^{b_{j}} c_{i j l}}{\sum_{l=1}^{b_{j}} w_{j l}},
$$




$$
\hat{R}_{i}=\frac{\sum_{j=1}^{h}\left[V_{j} \frac{\sum_{l=1}^{b_{j}} c_{i j l}}{\sum_{l=1}^{b_{j}} w_{j l}}\right]}{\sum_{j=1}^{h} V_{j}}
$$

$\widehat{\operatorname{Var}}\left(\hat{R}_{i j}\right)=\frac{\left(1-\frac{b_{j}}{B_{j}}\right)}{b_{j} \bar{w}_{j}^{2}} \frac{\sum_{l=1}^{b_{j}}\left(c_{i j l}-\hat{R}_{i j} w_{j l}\right)^{2}}{\left(b_{j}-1\right)}$,

which, when $B_{j}$ is very large, simplifies to

$\widehat{\operatorname{Var}}\left(\hat{R}_{i j}\right)=\frac{\sum_{l=1}^{b_{j}}\left(c_{i j l}-\hat{R}_{i j} w_{j l}\right)^{2}}{\bar{w}_{j}^{2} b_{j}\left(b_{j}-1\right)}$,

and where

$\bar{w}_{j}=\frac{\sum_{l=1}^{b_{j}} w_{j l}}{b_{j}}$.

Asymptotic $(1-\alpha) \quad 100 \%$ CI estimates for $\hat{E}_{i}$ can be calculated as

$\hat{E}_{i} \pm Z_{1-\frac{\alpha}{2}} \sqrt{\widehat{\operatorname{Var}}\left(\hat{E}_{i} \mid E_{i}\right)}$

\section{Estimating the Entrainment Rate}

The entrainment rate $\left(R_{i}\right)$ for the $i$ th age class of crab can be defined by Equation (5) or equivalently as the ratio of the total number of crab entrained to the total volume of dredged material collected where

$$
R_{i}=\frac{E_{i}}{\sum_{j=1}^{H} V_{j}}
$$

The entrainment rate $\left(R_{i}\right)$ can be estimated by the ratio 


$$
\hat{R}=\frac{\hat{E}_{i}}{\sum_{j=1}^{H} V_{j}}
$$

with associated variance estimator

$$
\widehat{\operatorname{Var}}\left(\hat{R}_{i} \mid R_{i}\right)=\frac{\widehat{\operatorname{Var}}\left(\hat{E}_{i} \mid E_{i}\right)}{\left[\sum_{j=1}^{H} V_{j}\right]^{2}} .
$$

Estimating Adult Equivalent Loss (AEL)

The estimate of AEL for the Dungeness crab entrainment can be expressed as follows:

$$
\widehat{A E L}=\sum_{i=1}^{A} \hat{E}_{i} \cdot \hat{M}_{i} \cdot \hat{S}_{i}
$$

where

$$
\begin{aligned}
\hat{E}_{i}= & \text { estimate of total crab entrained of age class } i(i=1, \ldots, A) \\
\hat{M}_{i}= & \text { estimate of direct mortality associated with the dredging operation on crab entrained of } \\
& \text { age class } i(i=1, \ldots, A) \\
\hat{S}_{i}= & \text { estimate of the survival probability from age class } i(i=1, \ldots, A) \text { to age of interest } \\
A= & \text { number of age classes (i.e., } 2+\text { or } 3+) .
\end{aligned}
$$

Estimates of $\hat{M}_{i}$ and $\hat{S}_{i}$ used in the assessment did not have associated variance estimators. Hence, the contribution of $\operatorname{Var}\left(\hat{M}_{i}\right)$ and $\operatorname{Var}\left(\hat{S}_{i}\right)$ could not be propagated to the overall variance of the AEL estimates. Instead, $\hat{M}_{i}$ and $\hat{S}_{i}$ were treated as known constants when calculating the variance of $\widehat{A E L}$. In which case,

$$
\widehat{\operatorname{Var}}(\widehat{A E L})=\sum_{i=1}^{A}\left[\operatorname{Var}\left(\hat{E}_{i} \mid E_{i}\right) \cdot \hat{M}_{i}^{2} \cdot \hat{S}_{i}^{2}\right]
$$

Equation (9) will underestimate the true variance of the AEL estimates when $\hat{M}_{i}$ and $\hat{S}_{i}$ are measured with error.

Estimating Loss to Fishery (LF)

The LF of harvestable crab was estimated by the quantity 


$$
\widehat{L F}=\hat{H} \cdot \sum_{i=1}^{A} \hat{G}_{i} \hat{E}_{i} \hat{M}_{i} \hat{S}_{i}
$$

where

$$
\begin{aligned}
& \hat{G}_{i}=\text { estimated fraction of the } i \text { th age class composed of males } \\
& \hat{H}=\text { estimated probability of harvesting a male crab in the Dungeness fishery. }
\end{aligned}
$$

Again, assuming the values of $\hat{G}_{i}$ and $\hat{H}$ are known constants, the variance of $\widehat{L F}$ can be estimated by the formula

$$
\widehat{\operatorname{Var}}(\widehat{L F})=\hat{H}^{2} \cdot \sum_{i=1}^{A}\left[\widehat{\operatorname{Var}}\left(\hat{E}_{i} \mid E_{i}\right) \cdot\left(\hat{G}_{i} \cdot \hat{M}_{i} \cdot \hat{S}_{i}\right)^{2}\right]
$$

Equation (11) will underestimate the true variance of $\widehat{L F}$ when $H$ and $G_{i}$ are measured with error. 


\subsection{RESULTS}

\subsection{Direct Measurements of Crab Entrainment}

While the Corps' dredge Essayons was conducting maintenance and operations dredging at the MCR, the scientific team made direct measurements of crab entrainment (Table 1, Figure 1). Six periods of sampling corresponded with six periods of dredging (Table 1). The bulk of dredging occurred between $\mathrm{RM}+1$ and RM+2 (338 loads) over three separate periods (late July, late August to mid September, and mid October). Between July 9 and October 13, 2002, the team took samples from over 2.75 million cy of material that the Essayons dredged from the MCR. During this time, the team sampled 214 of the total of 489 loads dredged at the MCR to yield a total of 643 basket samples. The data from these samples are provided in Appendix A.

\subsection{Entrainment Rates $(\mathbf{R})$}

Dungeness crab were found in the entrainment samples at the MCR in a contagious distribution, i.e. many samples had no crab, some had one to three crab, and only a few had more than four crab per basket sample (Appendix A). The entrainment rate for all age classes over all sampling in the MCR was 0.0603 crab per cy (Table 3$)$. Age $2+$ crab had the highest entrainment rate $(0.0322$ crab per cy) in the MCR while the $0+$ crab had the lowest $(0.0033$ crab per cy). Of the six sampling periods, sampling Period 5 in the MCR from RM-2 to RM0 in October had the highest entrainment rate ( 0.1789 crab per cy).

Entrainment rates in the other sampling periods generally varied over a narrow range from 0.049 to 0.066 crab per cy.

Over time, the entrainment rates for the $1+$ crab in the MCR generally decreased, as those for the $2+$ and older crab appeared to increase (Table 3 ). The regression of the entrainment rates for $1+$ crab against the entrainment rates of the $2+$ and older crab was inverse and significant $(p=0.022)$ with an $R^{2}$ of $77 \%$.

Sex ratios of the older crab entrained in the MCR were notably skewed to females (Appendix A). The sex ratio was not significantly different from $1: 1$ for $0+$ crab but was significantly different from 1:1 for the other age classes. For $1+, 2+$, and $3+\mathrm{crab}$, the percentages that were female were $61 \%, 82 \%$, and $83 \%$, respectively.

Other species entrained in moderate numbers in the MCR included Crangon shrimp, razor clams (Siliqua patula), Pacific sand lance (Ammodytes hexapterus), Pacific staghorn sculpin (Leptocottus armatus), and several other fish species (Appendix B).

\subsection{DIM Results for Dredged Volumes Accomplished in 2002 and for 5-year average Dredged Volumes}

The DIM was used to calculate the E, AEL at age 2+ and age 3+, and the LF for dredged volumes sampled aboard the Essayons in the summer of 2002 (Appendix A). Coefficients of variation associated with all these terms were under 5\%. Age class $2+$ and $3+$ crab contributed over $95 \%$ of the AEL + in the MCR (Appendix A). The DIM was also used to project the E, AEL at age $2+$ and age $3+$, and LF for total 2002 and annual 5-year average dredged volumes collected by both the Essayons and the contractor dredges (Table 4), although associated variance and confidence limit calculations were limited to Essayons 2002 volumes (Appendix C).

For the summer 2002 MCR Essayons dredged volume (3,017,176 cy), the estimated AEL at age 2+ was 118,326 crabs with $95 \%$ confidence limits from 107,300 to 129,352 crabs (Table 5). The estimated AEL 
at age $3+$ for summer 2002 was 53,247 crabs, with $95 \%$ confidence limits from 48,269 to 58,225 crabs. The projected LF for total summer 2002 MCR Essayons dredged volumes was 6,868 crabs with 95\% confidence limits from 6,256 to 7,480 crabs.

Because female crabs appeared in the entrainment samples at a higher rate than did males, the AEL estimates for females for the dredge volumes accomplished by the Essayons in 2002 were higher than

those for males (Appendix C, Table 6). The AEL estimates at age 2+ for the Essayons 2002 MCR total dredged volumes were 21,802 male crab and 96,524 female crab. Therefore, about $82 \%$ of the AEL at age 2+ in the MCR was comprised of female crab in 2002.

For the summer 2002 MCR total dredged volume (4,600,378 cy) collected by both Corps and contractor dredges, the estimated AEL at age 2+ was 180,416 crabs, estimated AEL at age 3+ was 81,187 crabs, and projected LF was 10,471 crab (Table 5). For the 5-year average total MCR dredged volumes $(4,391,872$ cy), the estimated AEL at age 2+ was 172,238 crabs, estimated AEL at age 3+ was 77,507 crabs, and projected LF was 9,997 crabs (Table 5).

\subsection{Salinity in Dredged Material Samples}

Salinity in dredged materials from the MCR was close to that of ocean water for most of the sampling from July to October 2002 (Figure 3). Salinity in the samples ranged from a minimum of 10.8 practical salinity units (PSU) to a maximum of 34.1 PSU with an average of 31.4 PSU. About $82 \%$ of the salinity measurements were above 32 PSU, 98\% were above 28 PSU, and less than $1 \%$ were below 16 PSU.

Entrainment rates did not correlate significantly with the high bottom salinities found in the MCR over all sampling periods. Using information obtained from each MCR sampling period, all regressions of the natural logarithm of the entrainment rates for various combinations of age classes against two measures of salinity ( $\%>32$ PSU and $\%<16$ PSU) were not significant (Table 7$)$. 


\subsection{DISCUSSION}

The entrainment rates reported here for the MCR coupled with those of Pearson et al. (2002) for the locations upriver from the MCR constitute a major step forward in quantifying crab entrainment in the Columbia River Estuary. The previous measurements of entrainment rates in the Columbia River were much more limited. For example, entrainment rates measured by Larson (1993) were restricted to the MCR, whereas the pilot sampling in March 2002 at Desdemona Shoals was restricted to a single day of sampling. Also, the statistical design employed in our study enabled calculation of confidence limits for the entrainment projections. Further, the statistical sampling design yielded precise estimates of entrainment, i.e., the CV for E, AEL, and LF were all less than 5\% and substantially below the target CV of $12.5 \%$.

The entrainment rates measured in the MCR in summer $2002(\mathrm{R}=0.06$ crab per cy for all age classes, Table 4) can be compared with those reported in previous studies. Larson (1993) reported annual average entrainment rates in the MCR ranging from 0.32 to $10.78 \mathrm{crab}$ per cy for $0+\mathrm{crab}$ and from 0.03 to 0.18 crab per cy for $1+$ and older crab. Therefore, the rates in the summer of 2002 for the MCR $(0.06 \mathrm{crab}$ per cy) are comparable to those of Larson (1993) for the MCR ( 0.03 to 0.18 crab per cy) for the 1+ and older crab. The summer $2002 \mathrm{MCR}$ entrainment rates for $0+$ crab were lower than those reported by Larson (1993). We attribute the relatively few 0+ crab found in the summer 2002 samples in the MCR to not having sampled in May and early June when large numbers of 0+ crab typically enter the lower estuary (Larson 1993; McCabe et al. 1986, 1989). Studies in the Grays Harbor estuary reported entrainment rates that ranged from 0.03 to 0.5 crab per cy (Wainwright et al. 1992). The rates of Wainwright et al. (1992) were derived from 14 surveys of 2 to 3 days each conducted over several years and included several locations with the estuary above the mouth. Entrainment rates for all age classes reported in Pearson et al. (2002) ranged from 0 to 0.224 crab per cy for upriver locations in the summer of 2002. Of the upriver locations sampled by Pearson et al. (2002), Desdemona Shoals (RM+4 to RM+7) is the closest to the MCR. Entrainment rates at Desdemona Shoals in June and September 2002 were 0.224 and 0.120 crab per cy, respectively.

It should be noted that the entrainment rates reported and used here are based on sampling conducted during the summer months of a single year. Crab abundance and age-class distribution in the MCR is known to vary by season, and crab abundance can vary by three orders of magnitude from year to year (Larson 1993). Because of constraints imposed by weather and wave climate, dredging in the MCR is limited to late spring, summer, and early fall. This study has sufficient sampling in the summer and early fall to yield highly precise estimates (CV less than 5\%), though sampling in the late spring would be advantageous to further clarify trends over the typical dredging time period.

The losses estimated for the MCR are directly comparable to estimates for upriver locations to be dredged under the Channel Improvement Project. For the 5-year average total annual MCR dredged volumes $(4,391,872 \mathrm{cy} /$ year), the estimated annual AEL at age $2+$ was $172,238 \mathrm{crab}$ (Table 5). The annual LF projected for the MCR was 9,997 crab. These LF values in the MCR represent about $0.2 \%$ of the annual crab landings for the Washington and Oregon region around the Columbia River (5.3 million crab from 1991 to 2001). The estimates of Pearson et al. (2002) for the Channel Improvement Project forecast a loss of approximately 38,811 to 281,528 age $2+$ crab for the combined construction increments, and of 51,115 to $101,483 \mathrm{crab}$ for annual maintenance. These estimates correspond to fishery losses of approximately 7,252 to 44,342 age $3+$ male crab for the combined construction increments, and of 8,052 to 15,984 age $3+$ male crab for annual maintenance. The worst-case projected fishery losses associated with the Channel Improvement Project represent approximately $1 \%$ of the annual crab landings for the Washington and Oregon region around the Columbia River. 
The projections for crab entrainment at the MCR have some assumptions that must be noted. Projections for material dredged in 2002 by the Essayons were presented with confidence limits because we sampled the same area using the same vessel. However, because we have no empirical data on entrainment rates for private contractor dredge efforts or for other years, projection rates for the contractor dredge and total effort was made with the following assumptions:

- Entrainment rates were the same across vessels

- Entrainment rates were the same across years (i.e., no changes in annual abundance)

- Dredging effort sampled the same distribution of entrainment rates (i.e., sampled similarly the distribution of abundances)

Because of these assumptions our projections are presented without additional measures of statistical precision. Likewise, the calculations made in this paper are constrained by many of the same assumptions noted by Armstrong et al. (1987), Wainwright et al. (1992), and Pearson et al. (2002) for estimates of crab size-at-age, mortality, survival, and exploitation rates.

Our annual 5-year average projections are based on dredged volumes reported by the Corps of Engineers over the federal fiscal year, which runs from October 1 of one year through September 30 of the next calendar year. As a federal agency, the Corps does this to meet fiscal budgeting requirements. Fiscal year dredged volumes, therefore, vary slightly from average volumes collected over a typical dredging season, which runs from May or June through October or November within a calendar year. Averaged over 5-years the total dredged volume by fiscal year and season are likely similar, although there will be discrepancies in any one year; no dredged volumes are omitted.

The salinities measured for the dredged materials in the MCR during summer 2002 were near or at oceanic salinities most of the time, and there was no significant relationship between the MCR entrainment rates and salinity. These results provide further evidence to support the analysis in Pearson et al. (2002) analysis that where bottom salinities are high most of the time, factors other than salinity are influencing crab distribution and entrainment rates. The results reported here, coupled with those in Pearson et al. (2002), indicate that low salinity influences crab-entrainment rates. Where bottom salinities are less than 16 PSU most of the time (i.e., Miller Sands [RM +21 to RM +24] in late summer 2002), crab-entrainment rates are zero (Pearson et al. 2002). When the entrainment rates for the MCR and the upriver locations are considered together, regressions between the natural logarithm of crab-entrainment rate for $2+$ and older crab and the percentage of salinity observations below 16 PSU were significant and explained a high degree $(91 \%)$ of the variation. Regressions of the natural logarithm of entrainment rates for $1+$ crab and the percentage of salinity observations above 32 PSU and below 16 PSU were not significant. Age $1+$ crab represented a low percentage $(<10 \%)$ of the crab found in the MCR (Table 4$)$, and the relationship between salinity and the entrainment rate of $1+$ crab appears to be more complex than that for the $2+$ and older crab.

The scientific literature, scenario analyses (Pearson et al. 2002), and the summer 2002 site-specific data (Pearson et al. 2002; this study) on entrainment and salinity all indicate that bottom salinity influences crab distribution, especially at lower salinities. However, the model for the influence of salinity on crab distribution and entrainment needs further development to clarify the finer points of this relationship. 


\subsection{REFERENCES}

Armstrong, David A., T. C. Wainwright, J. Orensanz, P. A. Dinnel, and B. R. Dumbauld. 1987. Model of Dredging Impact on Dungeness Crab in Grays Harbor, Washington. Fisheries Research Institute, University of Washington, School of Fisheries; FRI-UW-8702.

Larson, Kim W. 1993. Entrainment of Dungeness Crab by Hopper Dredge at The mouth of The Columbia River, OR and WA. U.S. Army Corps of Engineers, Portland District; 1993.

McCabe, G. T. Jr., R. L. Emmett, T. C. Coley, and R. J. McConnell. 1986. Distribution, abundance, and size-class structure of Dungeness crab in the Columbia River Estuary. National Marine Fisheries Service, 2725 Montlake Boulevard East, Seattle, WA. Final Report to Portland District, U.S. Army Corps of Engineers, Contract DACW57-84-F-0178. 57 pp.

McCabe, G. T. Jr., and R. J. McConnell. 1989. Abundance and size-class structure of Dungeness crab in our near frequently dredged areas in the Columbia River estuary. National Marine Fisheries Service, 2725 Montlake Boulevard East, Seattle, WA. Report to Portland District, U.S. Army Corps of Engineers, P.O. Box 2946, Portland, OR 97208-2946. 22 pp.

Pearson, W.H. 1987. Conclusions of the Third Meeting of the Crab Study Panel Examining Issues Related to Dungeness Crab for the Grays Harbor Navigation Improvement Project. PNL-6257.

Prepared for the U.S. Army Corps of Engineers, Seattle District, by Battelle/Marine Sciences Laboratory, Sequim, Washington.

Pearson, W.H., G.D. Williams, and J.R. Skalski. 2002. Estimated Entrainment of Dungeness Crab During Dredging for the Columbia River Channel Improvement Project. PNNL-14129. Prepared for the U.S. Army Corps of Engineers, Portland District, by Battelle Marine Sciences Laboratory, Sequim, Washington. Published by Pacific Northwest National Laboratory, Richland, Washington.

Pearson, W.H. and D.L. Woodruff. 1987. Effects of Proposed Dredged Materials from Grays Harbor on Bait Odor Response in Dungeness Crab ( Cancer magister). PNL-6436. Prepared for the U.S. Army Corps of Engineers, Seattle District, by Battelle/Marine Sciences Laboratory, Sequim, Washington. Published by Pacific Northwest Laboratory, Richland, Washington.

Pearson, W.H., D.L. Woodruff, P. Wilkinson, J.S. Young, H.L. McCartney, and D.C. Klopfer. 1987. Data Report for the 1984-1985 Ocean Surveys to Investigate Potential Ocean Disposal Sites off Grays Harbor, Washington. PNL-6280. Prepared for the U.S. Army Corps of Engineers, Seattle District, by Battelle/Marine Sciences Laboratory, Sequim, Washington. Published by Pacific Northwest Laboratory, Richland, Washington.

Rooper, C.N, D.A. Armstrong, and D.R. Gunderson. 2002. Habitat Use by Juvenile Dungeness Crab in Coastal Nursery Estuaries. Crab in Cold Water Regions: Biology, Management, and Economics. Alaska Sea Grant College Program, Publication AK-SG-02-01. pp. 609-629.

Tasto, R.N. 1983. Juvenile Dungeness crab, Cancer magister, studies in the San Francisco Bay area, pp. 135-154. In: P.W. Wild and R.N Tasto (eds) Life History, Environment and Mariculture Studies of the Dungeness Crab, Cancer magister, with Emphasis on the Central California Fishery Resource. Fish Bulletin 172 of the Department of Fish and Game, State of California. 
Wainwright, T.C., D.A. Armstrong, P.A. Dinnel, J.M. Orensanz, and K.A. McGraw. 1992. Predicting the effects of dredging on a crab population: An equivalent adult loss approach. Fishery Bulletin 90:171182.

Wainwright, T.C.; K.A. McGraw, D.A. Armstrong, B.R. Dumbauld, and L.L. Conquest. 1990. Impact of Dredging on Dungeness crab, Cancer magister, in Grays Harbor, Washington, during August 1989. Fisheries Research Institute, University of Washington, School of Fisheries; 1990; FRI-UW-9005. 


\subsection{FIGURES}

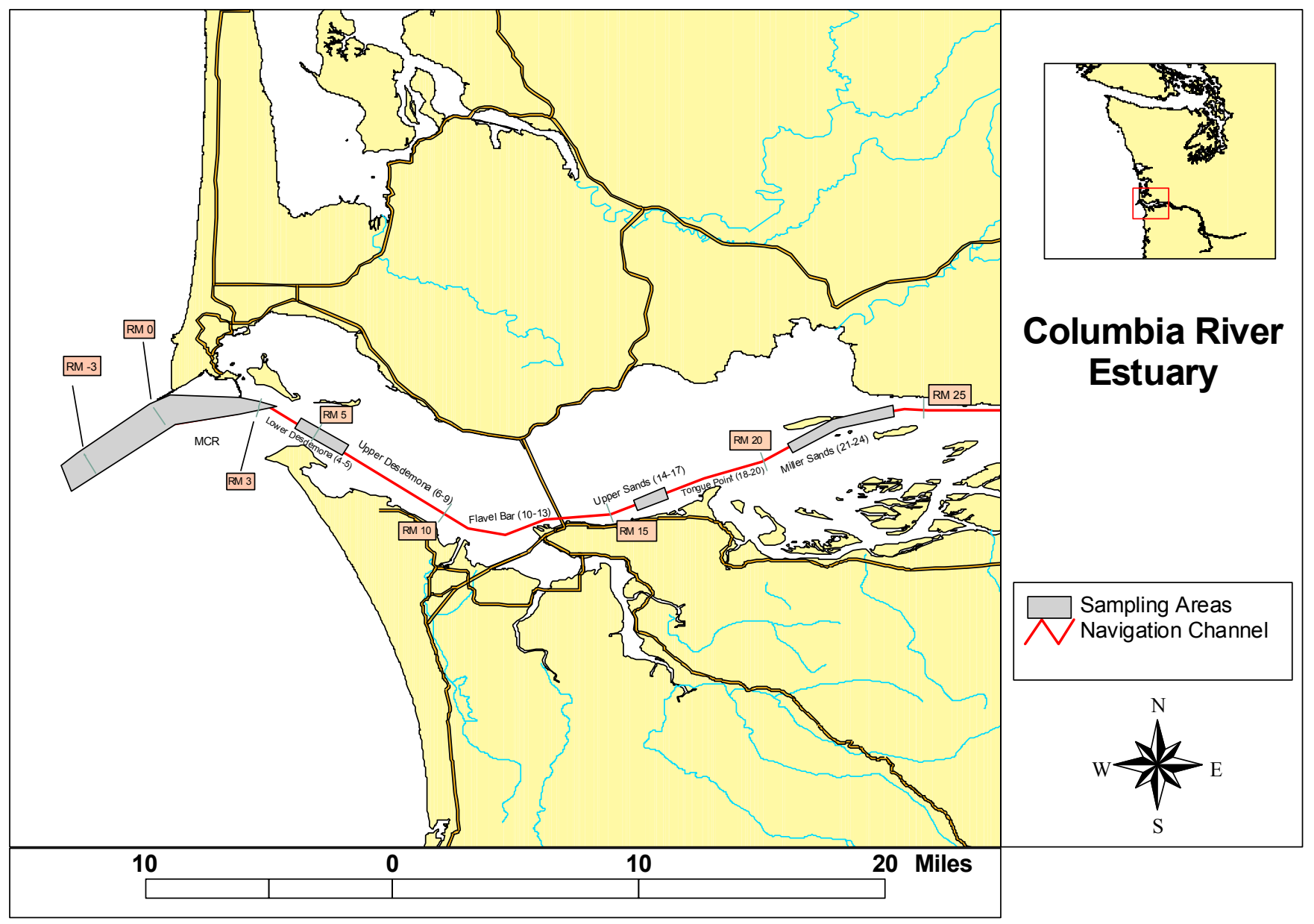

Figure 1. Map of Study Area, Summer 2002. 




Figure 2. Diagram of the Piping and Valving on the Corps' Dredge Essayons, Summer 2002.

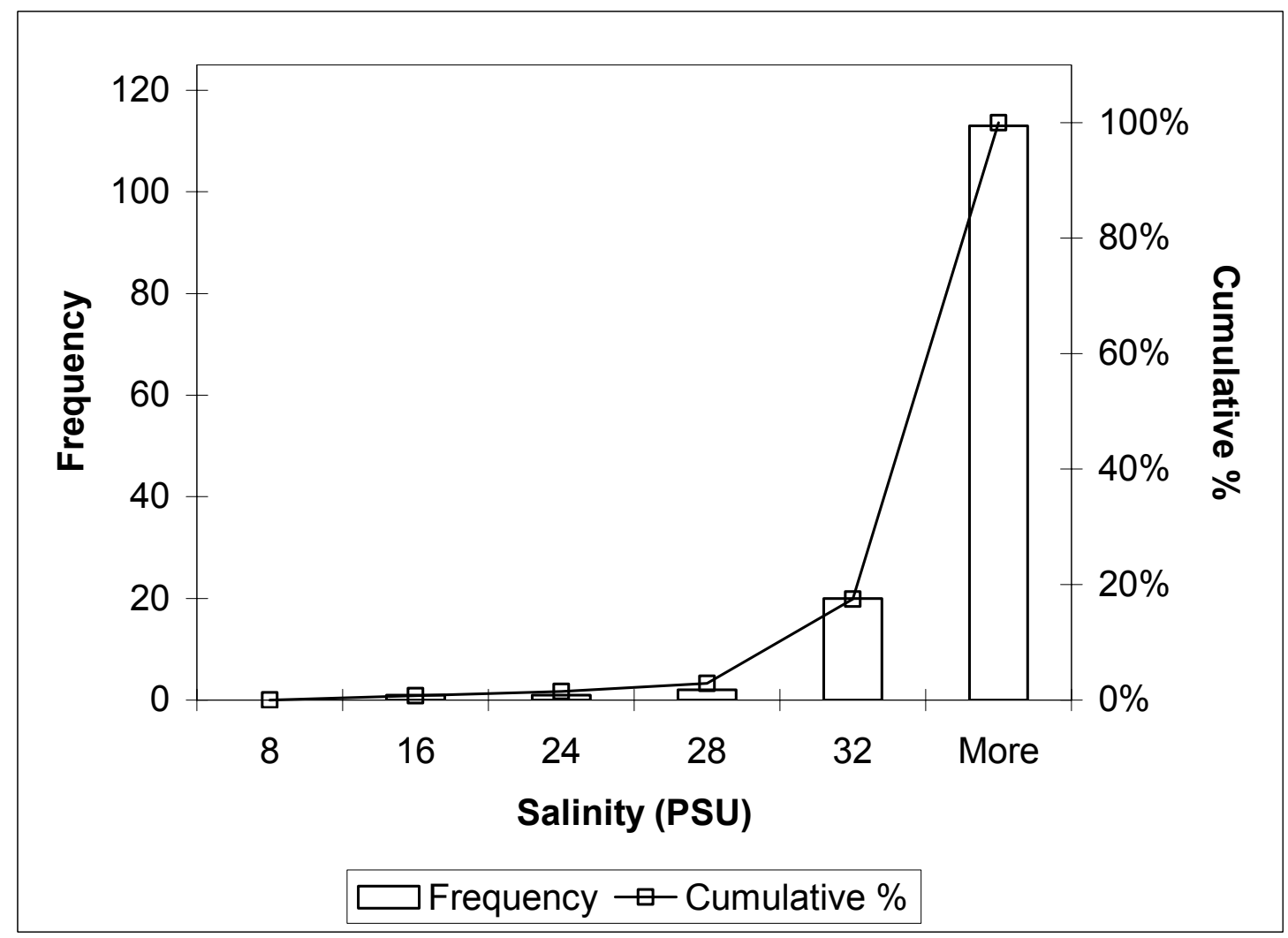

Figure 3. Histogram of Salinity (PSU) in Dredged Material Samples from the MCR in Summer 2002. 


\subsection{TABLES}

Table 1. Sampling Effort Associated with MCR Crab Entrainment Sampling on the Dredge Essayons During Summer 2002.

\begin{tabular}{|c|c|c|c|c|c|c|}
\hline Location & River Mile & Dates (2002) & $\begin{array}{c}\text { Total } \\
\text { Dredged } \\
\text { Volume (cy) } \\
\end{array}$ & $\begin{array}{c}\text { Total } \\
\text { Loads } \\
\text { Dredged } \\
\end{array}$ & $\begin{array}{c}\text { Total } \\
\text { Loads } \\
\text { Sampled } \\
\end{array}$ & $\begin{array}{c}\text { Total } \\
\text { Basket } \\
\text { Samples } \\
\end{array}$ \\
\hline MCR - 1 & -2 to +2 & 9 to $21 \mathrm{JUL}$ & 563,024 & 101 & 47 & 142 \\
\hline MCR - 2 & +1 to +2 & 23 to $31 \mathrm{JUL}$ & 498,841 & 85 & 40 & 120 \\
\hline MCR - 3 & +1 to +2 & 24 AUG to 16 SEP & $1,208,404$ & 212 & 85 & 255 \\
\hline MCR - 4 & -1 to +1 & 18 to 22 SEP & 255,395 & 46 & 22 & 66 \\
\hline MCR - 5 & -2 to 0 & 8 to 9 OCT & 34,360 & 7 & 3 & 9 \\
\hline MCR - 6 & +1 to +2 & 9 to $13 \mathrm{OCT}$ & 203,095 & 38 & 17 & 51 \\
\hline All MCR & -2 to +2 & $9 \mathrm{JUL}$ to $13 \mathrm{OCT}$ & $2,763,119$ & 489 & 214 & 643 \\
\hline
\end{tabular}

Table 2. Coefficients of Variation for Different Numbers of Basket Samples per Dredge Load. Based on Data from June 2002. Note: The column for 0+ crab uses all 17 loads of which only 5 detected $0+$ age class; precision calculations based on only the loads with observed crab yields a CV of 0.114 for 2 basket samples per load.

\begin{tabular}{|c|c|c|c|c|}
\hline \multirow{2}{*}{$\begin{array}{c}\text { Basket } \\
\text { Samples } \\
\text { per Load }\end{array}$} & \multicolumn{4}{|c|}{ Age Class } \\
\hline & $\mathbf{0}+$ & $1+$ & $2+$ & $3+$ \\
\hline 1 & 0.185 & 0.064 & 0.151 & 0.268 \\
\hline 2 & 0.149 & 0.049 & 0.103 & 0.24 \\
\hline 3 & 0.135 & 0.043 & 0.086 & 0.23 \\
\hline 4 & 0.127 & 0.04 & 0.076 & 0.224 \\
\hline 5 & 0.122 & 0.038 & 0.07 & 0.221 \\
\hline
\end{tabular}


Table 3. Entrainment Rates by Crab Age Class from Direct Measurements in Summer 2002.

\begin{tabular}{|l|c|c|c|c|c|}
\hline & \multicolumn{5}{|c|}{ Age Class } \\
\hline Area & $0+$ & $1+$ & $2+$ & $3+$ & All \\
\hline MCR - 1 & 0.0022 & 0.0117 & 0.0408 & 0.0109 & 0.0656 \\
\hline MCR - 2 & 0.0024 & 0.0263 & 0.0194 & 0.0009 & 0.0490 \\
\hline MCR - 3 & 0.0031 & 0.0132 & 0.0313 & 0.0134 & 0.0609 \\
\hline MCR - 4 & 0.0028 & 0.0091 & 0.0274 & 0.0137 & 0.0530 \\
\hline MCR - 5 & 0.0741 & 0.0000 & 0.0649 & 0.0399 & 0.1789 \\
\hline MCR - 6 & 0.0000 & 0.0075 & 0.0462 & 0.0080 & 0.0617 \\
\hline MCR (Total) & 0.0033 & 0.0144 & 0.0322 & 0.0104 & 0.0603 \\
\hline
\end{tabular}

Table 4. Annual Dredged Volumes for the Mouth of the Columbia River, 1998-2002, Based on Federal Fiscal Years.

\begin{tabular}{|c|c|c|c|}
\hline \multirow{2}{*}{ Year } & \multicolumn{3}{|c|}{ Volumes Dredged in MCR (cy) } \\
\cline { 2 - 4 } & Essayons & Contractor & Total \\
\hline 1998 & $2,755,960$ & $1,499,318$ & $4,255,278$ \\
\hline 1999 & $1,817,065$ & $2,400,000$ & $4,217,065$ \\
\hline 2000 & $2,893,441$ & $1,924,164$ & $4,817,605$ \\
\hline 2001 & $2,318,583$ & $1,750,450$ & $4,069,033$ \\
\hline 2002 & $3,017,176$ & $1,583,202$ & $4,600,378$ \\
\hline Average & $2,560,445$ & $1,831,427$ & $4,391,872$ \\
\hline
\end{tabular}

Table 5. Summary of Entrainment Rates (R), Entrainment (E), Adult Equivalent Loss (AEL), and Loss to Fishery (LF) for the Total Dredged Volumes Accomplished in the MCR During Summer 2002 and for the Five-Year Average; Essayons Summer 2002 Projections Include 95\% Confidence Intervals (CI).

\begin{tabular}{|l|c|c|c|c|c|c|c|c|c|c|}
\hline Time Period & V (cy) & R & E & 95\%CI & AEL 2+ & 95\%CI & AEL 3+ & 95\%CI & LF & 95\%CI \\
\hline $\begin{array}{l}\text { Summer 2002 } \\
\text { (Essayons only) }\end{array}$ & $3,017,176$ & 0.0603 & 182,020 & $\pm 13,485$ & 118,326 & $\pm 11,062$ & 53,247 & $\pm 4,978$ & 6,868 & \pm 612 \\
\hline $\begin{array}{l}\text { Summer 2002 } \\
\text { (Total) }\end{array}$ & $4,600,378$ & 0.0603 & 277,532 & - & 180,416 & - & 81,187 & - & 10,471 & - \\
\hline $\begin{array}{l}\text { 5-Year Average } \\
\text { (Total) }\end{array}$ & $4,391,872$ & 0.0603 & 264,953 & - & 172,238 & - & 77,507 & - & 9,997 & - \\
\hline
\end{tabular}


Table 6. Contribution to Adult Equivalent Loss (AEL) by Male (M) and Female (F) Crab for 2002 Essayons Dredged Volumes.

\begin{tabular}{|c|c|c|c|}
\hline Age Class & Sex & AEL (Number) & \% of Total AEL \\
\hline $2+$ & M & 21,802 & 18.4 \\
\hline $2+$ & F & 96,524 & 81.6 \\
\hline $3+$ & M & 9,811 & 18.4 \\
\hline $3+$ & F & 43,436 & 81.6 \\
\hline
\end{tabular}

Table 7. Results of Regression Analysis Between Natural Logarithm of the Entrainment Rates and Percentage of Salinity Observations Above 32 PSU and Below 16 PSU for the MCR, Summer 2002. None of the regressions are significant.

\begin{tabular}{|c|c|c|c|}
\hline \multirow{2}{*}{$\begin{array}{c}\text { Salinity } \\
\text { Measurements }\end{array}$} & \multicolumn{3}{|c|}{ Entrainment Rates } \\
\cline { 2 - 4 } & All Ages & Age 1+ & Age 2+ \& 3+ \\
\hline$\%>32$ PSU & $\mathrm{p}=0.36$ & $\mathrm{p}=0.39$ & $\mathrm{p}=0.49$ \\
\hline$\%<16$ PSU & $\mathrm{p}=0.47$ & $\mathrm{p}=0.27$ & $\mathrm{p}=0.22$ \\
\hline
\end{tabular}


Appendices go here 
PNNL-14190

\section{DISTRIBUTION}

No. of

Copies

OFFSITE

10 Kim Larson

U.S. Army Corps of Engineers

Portland District

Environmental Resources CENWP-PE-E

P.O. Box 2946

Portland, OR 97208-2946

$1 \quad$ John R. Skalski

University of Washington

Fisheries Department

1325 4th Ave., Suite 1820

Box 358218

Seattle, WA 98101-2509

\section{ONSITE}

1 Greg D. Williams MSL

1 Walter H. Pearson MSL

1 Information Release K1-06 